\title{
Opening adress
}

If a congressist took some time to idle in the countryside near the location of this conference, he/she would encounter villages whose names sound familiar, like Saint Émilion, Sauterne and Margaux, to name but a few. Let us take some time to understand why they are well known. A first facet of this reputation is their age: these names have been known to travellers and gourmets for centuries - a reputation is not built in one day. A second facet is the age of the product they are known for: the age of the vineyard and the age of the wine. It takes time to shape a fine product. Time is probably a major component of the quality and fame of Bordeaux wines, and decades of refining know-how have resulted in the high standard they are known for.

If our fellow congressist entered a vinery, he/she would expect to see lines of wooden barrels, and dozens of skilful workers who take care of the production bottle by bottle, with love, because it has always been like this, and will ever be. Tradition is automatically associated with time needed to produce, and time needed to refine and polish. But it is no longer like this. There exist barrels, there exist workers who take care of the wine with love, but in a contemporary, high tech way. Wine production is well known for the high tech skills which it employs. Evolution has been very quick for the last few years. Bordeaux is known for the number of institutes contributing to oenology through molecular biology, for example.

As this conference demonstrates, it is the same for wood production. Every one has in mind the centuries needed to produce high quality oak timber, and every forest student here has been taught that the best oaks harvested today were planted in the time of Colbert, when overseas travels took as much time as we will soon need to fly to the planet Mars. Tradition is often associated with wood production, especially when quality, rather than quantity, is the goal. Once again, the current challenge for production of quality wood is combining the time needed to establish a reputation with high tech skills and the latest developments in molecular biology.

The outstanding quality of this conference is its success in linking both facets of production of quality wood: wood research is deeply concerned with current (r)evolutions in molecular biology.

Molecular biology has existed for several decades, and a landmark was the discovery of the molecular structure of DNA in 1953, although it had been known for longer that genetic information in chromosmomes was contained in a tiny strand of nucleic acid. There have been several revolutions since these pioneering times, especially since the develop- ment of equipment which allows routine descriptions of the variety of words written with A, T, C and G, leading to protein engeneering, modification of the activity of metabolic pathways and networks, and DNA chips which visualize the cooperation of genes. It is usual nowadays to distinguish between metabolic networks and gene regulation networks, both being the cornerstone of functional genomics and proteomics. This opens the door to the possibility of understanding multifactorial traits (such as growth, wood density and resistance to stress) as ouputs of gene regulation networks constantly operating within a sea of environmental signals, and lead quantitative genetics from empirical approaches into the framework of functional genetics.

In this context, wood quality is a new challenge. Indeed, it takes time to make wood, as it takes time to shape a new organism from a fertilized egg. The understanding of wood formation and quality requires the understanding of cell differentiation and ageing processes leading to the formation of early wood/late wood, sapwood/heartwood, etc. This requires understanding the roles and regulation of chemical signals for cell communication within an organism and between cells whose different genes are expressed, and is part of developmental biology. At the molecular level, regulating networks leading to wood formation are influenced by genes, environment, and cellular communication. This is a very "hot" research topic, which allows forest research to contribute to current frontiers of research in biology. Trees are invaluable vegetative material for studying ageing when compared with annual plants like Arabidopsis, for example.

One more word, to conclude. If our (virtual) congressist were to idle through some villages on particular days, whose dates are kept secret, he/she would encounter guilds of people, dressed in strange clothes, walking and playing music through the villages. They are the "confréries", who in a lively way remind us that those fellows who produce wine belong to the local community, and share the same mutual values. As far as the cooperative facet of research is concerned, this conference is an outstanding success as well, as its idea originated within several European research networks.

And, last but not least, it is a pleasure for me to thank Christophe Plomion, Christine Cahalan, Jean-Marc Frigerio, Marie-Pierre Reviron and all students of the "Forest Genetics" unit of INRA Pierroton for the wonderful organization of this conference, and for having given to all the participants the possibility to share current research ideas and to enjoy the unique taste of products of the Bordeaux area. 